\section{Entrevista: Domingos Sávio Alves}

Interview: Domingos Sávio Alves
Domingos Sávio do Nascimento Alves é médico neurologista e sanitarista, com especialização em Psiquiatria Social pela Escola Nacional de Saúde Pública Sergio Arouca, da Fundação Oswaldo Cruz (ENSP/Fiocruz). Desde a década de 1980, como médico e duas vezes diretor da Colônia Juliano Moreira, e durante os anos 1990, como coordenador da Área Técnica de Saúde Mental do Ministério da Saúde, tem sido um dos protagonistas do processo de Reforma Psiquiátrica no país. A partir do final da década de 1990 , além de consultor eventual do Ministério da Saúde, foi um dos diretores e último presidente do Instituto Franco Basaglia, organização não governamental do Rio de Janeiro que atuava na defesa dos direitos das pessoas com transtornos mentais. Nesta entrevista, ${ }^{1}$ Domingos aborda a presente e conflituosa situação da nomeação, ${ }^{2}$ pelo ministro da Saúde, de um inegável crítico da reforma e elabora uma breve análise dos principais avanços e desafios deste processo.
Domingos Sávio do Nascimento Alves is a neurologist and sanitarian, specialized in Social Psychiatry through the Sergio Arouca National School of Public Health, of the Oswaldo Cruz Foundation (ENSP/Fiocruz). Since the 1980s, as a physician, and twice as a director of the Juliano Moreira Colony, and during the 1990s, as the coordinator of the Ministry of Health's Mental Health Technical Area, he has been one of the main actors in the Psychiatric Reformation process in Brazil. From the 1990s, in addition to serving as an occasional consultant for the Ministry of Health, he also served as one of the directors and as the last chairman of the Franco Basaglia Institute, a Rio de Janeiro non-governmental organization that advocated the rights of people with mental disorders. In this interview, 1 Domingos addresses the current, conflicting situation of the Minister of Health's appointment ${ }^{2}$ of an undeniable critic of the reformation, and makes a brief analysis of the progress that has been made and of the challenges of this process. 


\section{Revista}

Qual o impacto que a nomeação do atual coordenador de saúde mental pode trazer para as políticas públicas de saúde mental do Brasil, sobretudo para o campo de álcool e drogas, considerando ainda o contexto de um Congresso Nacional conservador?

\section{Domingos Sávio Alves}

É evidente que uma política dessa complexidade, que tem menos de trinta anos de organização nacional em contraposição a outra forma de cuidado, que conta com mais de duzentos anos, sofre um impacto com a nomeação para a coordenação da política nacional de saúde mental de uma pessoa que possui uma trajetória diferente e afastada das diretrizes que sustentam a reforma psiquiátrica. Isso representa uma guinada que, do meu ponto de vista, tem impacto, sim. No desenvolvimento da reforma psiquiátrica, sempre foi possível contar com coordenadores que tinham clareza da necessidade de mudar o modelo assistencial, tal como expresso na I Conferência Nacional de Saúde Mental, de 1987, e na Declaração de Caracas, de 1990. Assim, quando é nomeada uma pessoa que tem dilemas e dúvidas em relação à pertinência dessa política, assumem-se riscos importantes para a velocidade de sua consolidação.

\section{Revista}

Como o senhor avalia os serviços oferecidos à população pela rede de atenção psicossocial?

\section{Domingos Sávio Alves}

Considerando que o principal serviço do cuidado, da atenção psicossocial são os centros de atenção psicossocial, os CAPS, eu analiso a política como exitosa, do ponto de vista da implantação e da rapidez de difusão desses serviços. A regulamentação é de 1991. Temos hoje 2.200 CAPS. Esses serviços, que são os principais para a substituição da internação e do hospital psiquiátrico, tiveram um incremento importante em todo o país. Não se trata de um esforço localizado, ainda que haja uma distribuição regional heterogênea. A cobertura é próxima de 0,7 por 100 mil habitantes, que é considerada boa. A expansão desses serviços, em termos quantitativos, é positiva, mas há também o reconhecimento de sua qualidade. O segundo serviço, também importante, são os residenciais terapêuticos/lares abrigados. Apesar de ainda existirem em pequeno número, mais de quatro mil pessoas já foram beneficiadas dentre as oitocentas residências terapêuticas implantadas. Hoje, ainda existem vinte mil pessoas hospitalizadas. Portanto, esse é um serviço dispositivo que precisa ser ampliado. São serviços dispositivos fundamentais, que expressam o compromisso ético da reforma psiquiátrica com aquelas pessoas que permaneceram por longo tempo internadas em hospitais psiquiátricos e que não têm uma casa/família para a qual retornar após a desospitalização. Outro componente também exitoso da política é o número de bolsistas do programa "De volta para casa", lei federal n. 10.708/2003 que institui o auxílio-reabilitação psicossocial para pacientes com transtornos mentais egressos de internações; e, antes ainda, lei municipal n. 3.400/2002, do Rio de Janeiro, que também concede bolsa de incentivo para integração de paciente com transtorno mental e história de longa permanência institucional na comunidade. Do ponto de vista da implantação dos elementos de suporte ao processo de desospitalização, estamos caminhando na direção certa. Mas persistem dificuldades na relação entre a atenção básica e a saúde mental, no atendimento no hospital geral e na questão de álcool e drogas.

\section{Revista}

Tanto o ministro da Saúde quanto o recém-nomeado coordenador de saúde mental, ao mesmo tempo em que fazem um discurso de defesa da reforma psiquiátrica, insistem que ela deve ser aprimorada. O que o senhor pensa a respeito? Quais ações seriam ainda necessárias para que a reforma se aperfeiçoe, caso o senhor considere que precisa ser aprimorada.

\section{Domingos Sávio Alves}

A primeira consideração que eu gostaria de registrar é que toda política pública necessita de aprimoramento. Políticas públicas têm que ser aprimoradas e avaliadas, e isso é um conceito importante, não deve ser uma particularidade da reforma psiquiátrica. Mas não me parece que a proposta de aprimoramento do atual ministro e do coordenador sejam semelhantes às que eu destaco. Apesar de defenderem a lei n. 10.216/2001 [que dispõe sobre a proteção e os direitos das pessoas com transtornos mentais e redireciona o modelo assistencial em saúde mental], eles têm 
uma perspectiva de humanização do hospital psiquiátrico que aponta para o fortalecimento dessa forma de cuidado. Evidentemente, as medidas de humanização são importantes e vêm sendo tomadas regularmente desde a década de 1990. Mas afirmo que uma política que indique a continuidade da hospitalização vai contra a lei. E não se trata de uma lei autoritária. Ao contrário, é o resultado e uma conquista de uma mobilização social intensa que envolveu, durante 12 anos, gestores, familiares, profissionais de saúde e usuários. $\mathrm{O}$ artigo quarto da lei determina que uma pessoa só pode ser cuidada em hospital psiquiátrico se não houver outro recurso terapêutico disponível. O aperfeiçoamento que eu indico vem sendo discutido e defendido em vários espaços. Recentemente, concluímos um seminário, promovido pela Organização Mundial da Saúde, a Organização Pan-Americana de Saúde, o Ministério da Saúde, a Plataforma Gulbenkian para a Saúde Mental Global e a Fundação Oswaldo Cruz, cujo relatório final elenca 21 recomendações para o aprimoramento da reforma psiquiátrica. Isso, por si, já explicita o reconhecimento da necessidade de aprimoramento, mas tais recomendações têm como eixo qualificar e de modo algum retroceder em relação ao processo em curso.

\section{Revista}

No atual cenário político, quais são os desafios estratégicos, de caráter mais imediato ou não, a serem enfrentados pela reforma psiquiátrica?

\section{Domingos Sávio Alves}

Para abordar esses desafios, tenho que fazer uma breve introdução. O cenário político é um cenário de baixíssima governabilidade, e isso já vem se dando há um ano, em decorrência das práticas de uma oposição que não aceita o resultado das eleições presidenciais e também da atuação de uma mídia majoritariamente militante na propagação dessa agenda negativa. Associa-se a isso uma crise econômica decorrente da crise política, que seguramente vem afetando as políticas públicas, as políticas sociais. Temos que considerar que há erros do governo e existe esse conflito, algo que podemos pensar como um 'patrocínio da intolerância', que é um elemento grave no cenário político e que repercute na economia. Nessas circunstâncias, o principal desafio é reverter, imediatamente, a nomeação do atual coordenador. Considerando que o conjunto de profissionais engajados na reforma psiquiátrica, majoritariamente, corroboram as críticas que mencionei anteriormente, devemos buscar, de forma política civilizada, franca e resoluta, a revogação dessa nomeação, que foi precipitada e equivocada. Tal nomeação não representa o momento atual da assistência psiquiátrica do país, e essa luta deve ser o primeiro movimento.

\section{Revista}

O senhor mencionou uma ação de caráter imediato. Considerando os desafios de curto e médio prazo, o que destacaria.

\section{Domingos Sávio Alves}

Identifico uma postura que, por vezes, assumimos no âmbito da gestão e que deveria ser mudada. Trata-se de continuar transferindo para o nível federal a responsabilidade de tudo que possa acontecer. Temos um capital político acumulado nos últimos vinte anos que não apenas nos autoriza, mas nos obriga a continuar fazendo bem, e melhor ainda, o que já vínhamos fazendo. É isso que nos legitima. Termos colocado em prática um tipo de cuidado que é, indiscutivelmente, superior ao que vinha sendo prestado. Portanto, nos cabe assumir nossas responsabilidades, cuidar dos nossos serviços e fazer uma forte articulação com estados e municípios E, sobretudo, com usuários e familiares. O SUS [Sistema Único de Saúde] não é somente o Ministério da Saúde. Nesse cenário político adverso, esses são desafios que se apresentam para a gente. Uma questão específica, por exemplo, que tem que ser enfrentada é a questão de álcool e drogas. Temos que lidar com esses problemas de saúde apoiados pelas novas propostas em curso, por um novo tipo de cuidado que se contraponha ao tratamento moral hoje hegemônico. Não tenho dúvida em afirmar - e tenho feito isso em diversas ocasiões - que existem estados cujas leis voltadas para a saúde mental violam a legislação federal ao fortalecerem o cuidado por meio de comunidades terapêuticas. É uma contradição que se agrava quando percebemos que o próprio governo federal financia esses projetos, cuja referência é o cuidado moral. Eu sei que parte dessa responsabilidade é nossa, por não termos conseguido prover um cuidado adequado e eficaz para esse tipo de transtorno mental. Contudo, agora que, do ponto de vista do financiamento e da diretriz política, temos instrumentos que 
sustentam outras práticas, devemos nos apropriar desses recursos para expandir a atenção baseada nos CAPS ad e demais dispositivos, como as unidades de acolhimento e consultórios na rua, para mudar essa situação da reinstitucionalização, que tem se tornado forte nos últimos anos.

\section{Revista}

Como as instituições de ensino poderiam colaborar com o enfrentamento de tais desafios?

\section{Domingos Sávio Alves}

Primeiro, eu gostaria de fazer uma consideração breve. Em geral, as instituições de ensino formam pessoas para o cuidado individual. A formação no campo da saúde não visa o cuidado coletivo. Há uma negação constante dessa perspectiva da saúde pública/coletiva e uma dificuldade de transmitir às pessoas em processo de formação, ou mesmo de capacitação, a necessária interlocução entre as diversas disciplinas. Isso se aplica ao ensino superior e ao ensino técnico. $\mathrm{O}$ ensino tende a reproduzir a hierarquia que tradicionalmente se observa no hospital. A hierarquia do conhecimento e do poder que se exerce no cotidiano: o médico dá ordens para a enfermeira, que dá ordem para o técnico, que vai construindo uma prática de segmentação. Essa reprodução ocorre mesmo em serviços abertos. As instituições de ensino deveriam ter o cuidado de, reconhecendo as especificidades de cada profissão, de cada especialidade, fortalecer e disseminar a necessidade de construir um conhecimento interdisciplinar. Vou retomar aqui a questão do cuidado em álcool e drogas, pois acho que encontramos aí um papel importante para as instituições de ensino. Atualmente, o espaço que o tratamento moral tem ocupado mantém relação com a atuação das instituições de ensino que, por exemplo, não ensinam, e isso seria realmente o mínimo, que as substâncias devem ser avaliadas do ponto de vista dos seus malefícios à saúde, e não do ponto de vista do catálogo da polícia federal, cuja lógica se baseia na criminalização. Isso é importante, e cabe às instituições de ensino incorporarem esse tema ao currículo. Outra questão, que envolve um elemento fundamental para a assistência, para o cuidado, é a integração entre a saúde mental e o campo da chamada medicina geral. Há uma dificuldade gritante em cuidar das emergências no hospital geral, há um déficit de leitos que tem que ser considerado. E também a questão da relação com a atenção básica. Em algumas cidades do interior, essa integração tem se mostrado forte, ao passo que em grandes cidades ela se dá de modo frágil e fragmentado. Isso é reflexo também de uma hegemonia do ensino baseado em serviços psiquiátricos tradicionais. Essa é uma preocupação que eu gostaria de ressaltar. Por último, ainda no que diz respeito às instituições de ensino, é importante fomentar crescentemente a pesquisa, tanto qualitativa quanto quantitativa. Os resultados de pesquisa têm o poder de ajudar a sustentar um discurso, para que possamos ter também uma sustentação científica renovada, além da sustentação política e a legitimação social adquiridas pelo processo de reforma psiquiátrica.

Domingos Sávio do Nascimento Alves es médico neurólogo y sanitarista, especializado en Psiquiatría Social en la Escuela Nacional de Salud Pública Sergio Arouca, de la Fundación Oswaldo Cruz (ENSP/Fiocruz). Desde la década de 80, como médico y dos veces director de la Colonia Juliano Moreira, y durante los años 90, como coordinador del Área Técnica de Salud Mental del Ministerio de la Salud, ha sido uno de los protagonistas del proceso de Reforma Psiquiátrica en el país. A partir de finales de la década de 90, además consultor eventual del Ministerio de la Salud, fue uno de los directores y último presidente del Instituto Franco Basaglia, organización no gubernamental de Río de Janeiro que actuaba en la defensa de los derechos de las personas con trastornos mentales. En esta entrevista, 1 el Dr. Alves aborda la presente y conflictiva situación del nombramiento, ${ }^{2}$ por parte del ministro de la Salud, de un innegable crítico de la reforma y elabora un breve análisis de los principales avances y desafíos de este proceso. 


\section{Notas}

1 Entrevista concedida ao Grupo de Trabalho em Saúde Mental, do Laboratório de Atenção à Saúde da Escola Politécnica de Saúde Joaquim Venâncio, Fundação Oswaldo Cruz (GTSM/Laborat/EPSJV/Fiocruz).

2 A nomeação em pauta é a do médico Valencius Wurch, que foi diretor da Casa de Saúde Dr. Eiras, de Paracambi. Esta instituição foi denunciada por maus-tratos aos pacientes, confirmados em relatório do ano 2000 da Comissão de Direitos Humanos da Câmara dos Deputados e em auditoria especializada do Ministério da Saúde. Por ordem judicial, esse manicômio psiquiátrico foi fechado em 2012. 